\title{
LI-FI: Light Fidelity-The Transmission of Data through Light
}

\author{
K. Sasirekha \\ III year ECE, Manakula Vinayagar Institute of Technology, Pondicherry
}

\begin{abstract}
Li-Fi or Light Fidelity or $5 G$ visible Light communication is a Latest technology using Light Emitting Diodes to transmit data similar to Wi-Fi. In this days the people who are all in need for the Wi-Fi hotspot has increased tremendously Li-Fi or New Life of data communication is a better alternative to Wi-Fi in wireless communication. This paper proposes a survey on Li-Fi Technology. The Li-fi technology was invented by Professor Harald Hass of University of Edinburgh. Li-Fi has more capacity in terms of bandwidth in visible region therefore it does not poke its nose in other communications which uses radio frequency range, without taking its frequency bands. Li-Fi has thousand times greater speed than Wi-Fi and provides security as the visible light is unable to penetrate through the walls, which propose a new era of wireless communication. The concept of is data communication on fast flickering of light which is not detected by human eye but it is focused on photo detector which converts the on-off state into binary digital data. It has gained a huge popularity in two years of its invention. Such technology has brought not only greener but safer and cheaper future of communication. This paper introduces this concept.
\end{abstract}

Keywords: LED (Light Emitting Diode), Wi-Fi (Wireless Fidelity), Li-Fi (Light Fidelity), VLC (Visible Light Communication), RF (Radio Frequency)

\section{Introduction}

The transfer of data from one place to another place is one of the important activities. We all know that the current network has many issues it is very slow when many elements are connected and it is takes a lot of time to transmit data if there are more number of interferences which is due to the fixed bandwidth. The radio waves are just the small part of spectrum available for data transfer. Instead of using radio waves we use light. We know that light can travel anywhere and anyplace and its very faster when compared to the radio waves used to transmit data in Wi-Fi and we can transmit enormous amount of data when compared to the Wi-Fi, with these enormous amount of speed 18 movies can be downloaded in a second. That is it transmits data at a speed up of 224 gigabits per second.

LI-FIis the technology which is used.LI-FI is Light fidelity. The term was first coined by the Pure LI-fi CSO, Professor Harald Haas in his TED talk in 2011 and refers to light based communications technology that delivers a highspeed, bidirectional networked, mobile communications in a similar manner as Wi-Fi.Li-Fi is the method of visible light communication. $\mathrm{Li}-\mathrm{Fi}$ is the transmission of data through light by taking out fibre from fibre optics and sending the data through the LED light. Instead of the Wi-Fi modems,Li-fi uses the transceivers fitted to the LED bulb which would light up the room and also transmits the data and also receive the information. Since simple light bulbs are used there can be any number of access points.

It has been designed to overcome the disadvantages of the Wi-Fi technology .It is more cost efficient when compared to the Wi-Fi .It can transmit data even under the water which is very useful in the military operations. The physicists envisions that this technology would make a great difference in the near future.

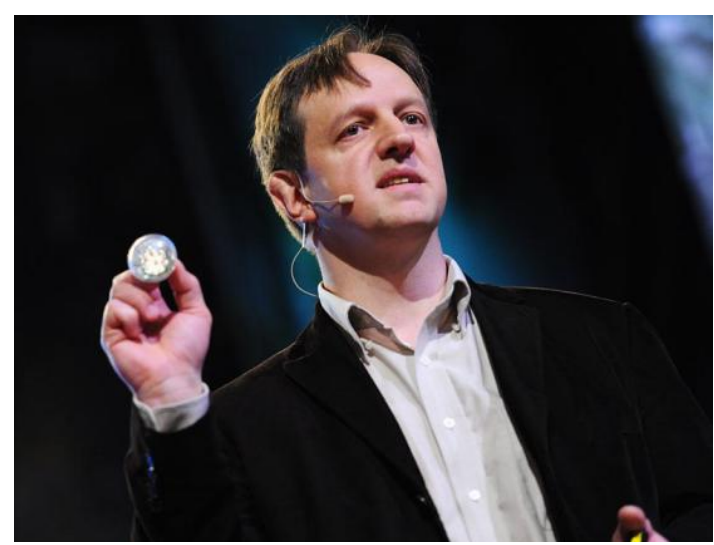

Figure 1: Professor Harald Haas

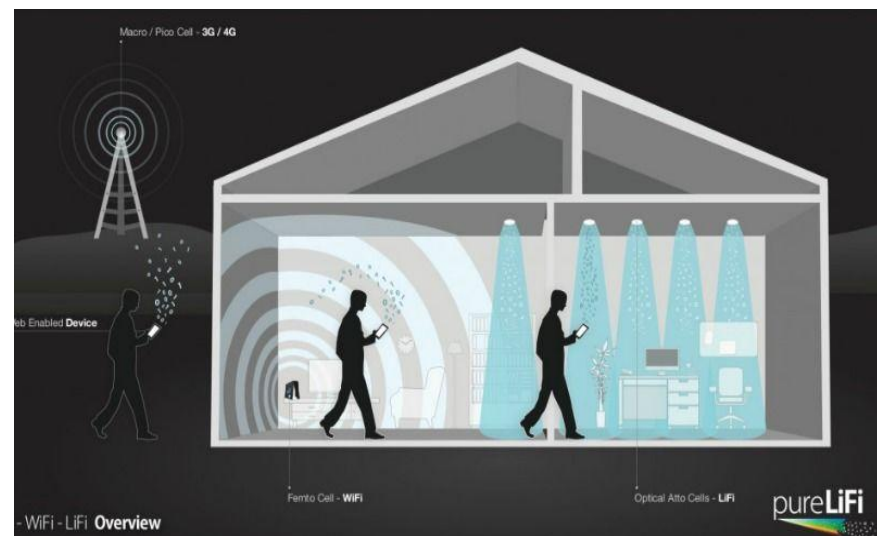

Figure 2: Li-Fi

\section{History}

Professor Harald Haas first coined the term "Li-Fi" at his TED talk in 2011 where he introduced the idea of "wireless data from every light", The D-light project. He is the chairman of the mobile communication at the University of Edinburgh and co-founder of the PureLiFi.LI-Fi has the technology to change how we access the internet, stream videos, receive mails and much more. The technology truly 


\section{International Journal of Science and Research (IJSR) \\ ISSN (Online): 2319-7064}

Index Copernicus Value (2015): 78.96 | Impact Factor (2015): 6.391

began during the 1990's in countries like Germany, Korea and Japan where they discovered LED's could be retrofitted to send the information. This type of light would come in familiar former such as infrared, ultraviolet and visible light .Research into VLC has been conducted in earnest since 2003 ,mainly in the UK, US .Experiments have shown that the LED can be electronically adapted to transmit the data wirelessly as well as to provide light .VLC is faster and cheaper. In October 2011, companies and industry groups formed the Li-Fi consortium to promote the high speed optical wireless systems and to overcome the limited amount of radio-based wireless spectrum available by exploiting a completely different part of the electromagnetic spectrum. Recent integrated CMOS optical receivers for LI_FI systems are implemented in with avalanche photodiodes (APDS)which has a low sensitivity .In July 2015, IEEE has operated the APD in Geiger-mode as a single photo avalanche diode (SPAD) to increase the efficiency of energy usage and makes the receiver more sensitive. This operation could also be performed as a quantum-limited sensitivity that makes receivers detect weak signals far from the distance.
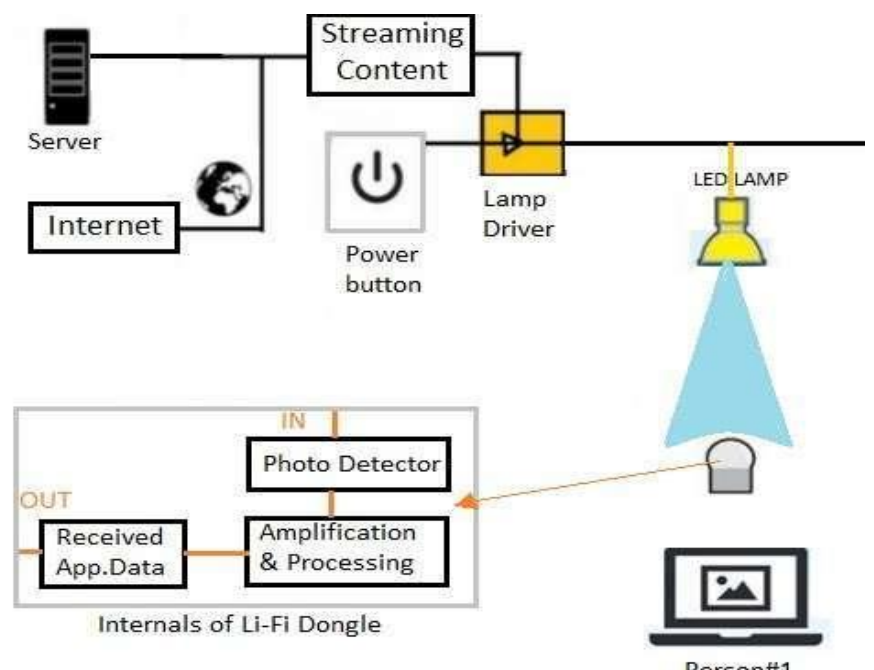

Figure 3: Li-fi internet architecture

\section{Working}

The system has two basic parts:

1) The LED bulb that transmits the modulated signals
2) A separate photo detector- a photodiode -connected to a computer or other internet enabled device that displays the decoded signals.

The LED bulb is a semiconductor light source, and the current can be modulated-by a microchip. The LED turns on and off at high speeds and is not visible to the human eye .The ribbon of on and off signals is interpreted to create binary streams of 0 and 1's.Communication rate greater than 100 MBPS is possible by using high speed LEDs with the help of various multiplexing technique such as spatial modulation -orthogonal, frequency division multiplexing or SM-OFDM, that enables a light source to transmit data and in an energy -efficient manner. VLC data rate can be increased by parallel data transmission using an array of LEDs where each LED transmits a different data stream.

The working of Li-Fi is very simple. There is a light emitter on one end, for example, an LED, and a photo detector (light sensor) on the other. The photo detector registers a binary one when the LED is on; and a binary zero if the LED is off. To build up a message, flash the LED numerous times or use an array of LEDs of perhaps a few different colours, to obtain data rates in the range of hundreds of megabits per second.

The data can be encoded in the light by varying the flickering rate of the LED to generate the digital strings such as 1 's and 0 's. The LED intensity is modulated so that the human eye won't be able to detect it.

Light-emitting diodes (commonly referred to as LEDs and found in traffic and street lights, car brake lights, remote control units and countless other applications) can be switched on and off faster than the human eye can detect, causing the light source to appear to be on continuously, even though it is in fact 'flickering'. The on-off activity of the bulb which seems to be invisible enables data transmission using binary codes: switching on an LED is a logical ' 1 ', switching it off is a logical ' 0 '. By varying the rate at which the LEDs flicker on and off, information can be encoded in the light to different combinations of $1 \mathrm{~s}$ and 0s.This method of using rapid pulses of light to transmit information wirelessly is technically referred toas Visible LightCommunication (VLC), though it is popularly called as $\mathrm{Li}-\mathrm{Fi}$ because it can compete with its radio-based rival $\mathrm{Wi}$ Fi. 


\section{International Journal of Science and Research (IJSR) \\ ISSN (Online): 2319-7064}

Index Copernicus Value (2015): 78.96 | Impact Factor (2015): 6.391

Four $10 \mathrm{Gbit} / \mathrm{s}$ optical hotspot user models:

- Wireless Docking ( -1cm)

- Near-Field "Wanding" (up to $\sim 25 \mathrm{~cm}$ )

Wireless "Data Showers" (up to $\sim 4 \mathrm{~m}$ )

"Beamed" Wireless Links (up to $\sim 10 \mathrm{~m}$ )

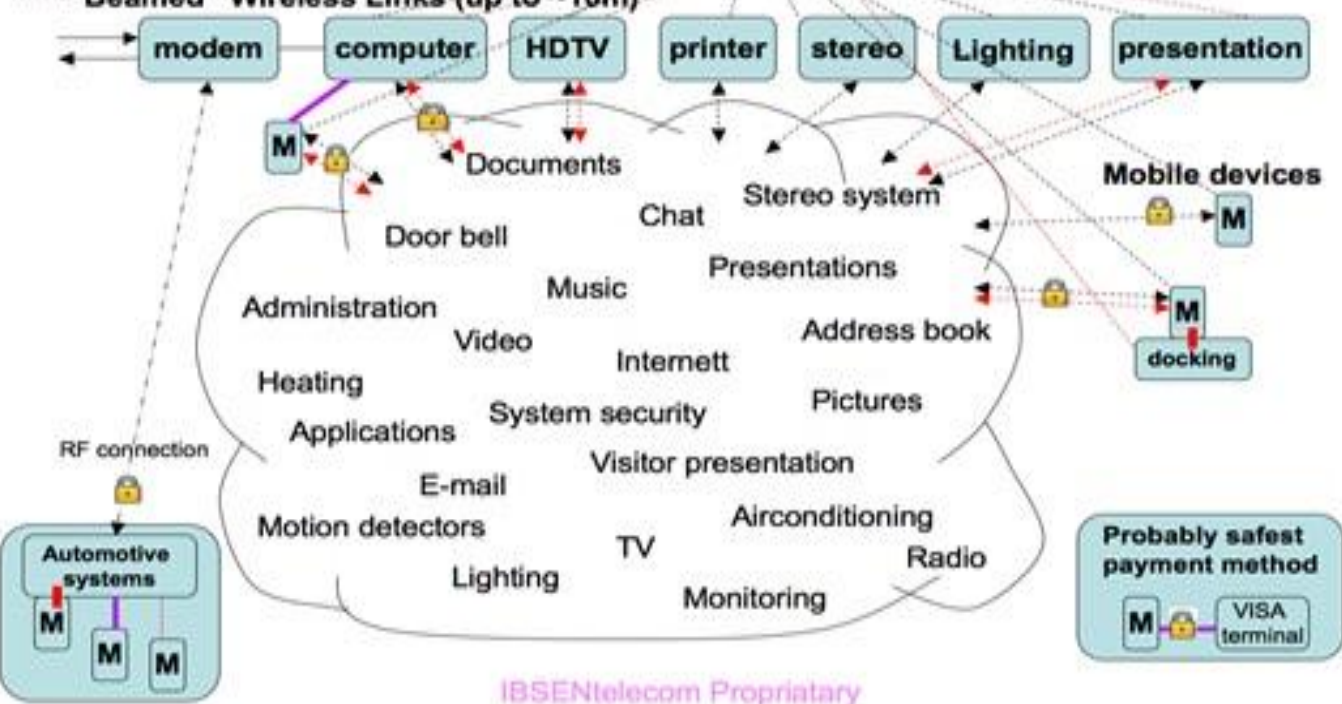

Figure 4: Li-Fi Communication with other devices.
$100 \mathrm{Mbit} / \mathrm{s}$ optical mobile communicaiton

\section{Lifi point}

\section{Comparison of Wi-Fi and $\mathrm{Li}-\mathrm{Fi}$}

\begin{tabular}{|c|c|c|c|}
\hline CHARACTERTSTICS & BLUETOOTH & WI-FI & LI-FI \\
\hline Frequency & $24 \mathrm{GHz}$ & $24 \mathrm{GHz}-5 \mathrm{GHz}$ & No frequener for Ight \\
\hline Range & 10 metss & 100 meters & Bassd on LED light faling \\
\hline Primary application & WPAN & WLANN & Where ever İght is avilable \\
\hline Data Transfer rate & SOOKCops & $11 \mathrm{M}$ Cos: & $>1$ Gops \\
\hline Powver Consumption & Iour & Medinum & Medium \\
\hline Cost & Iover & Medorim & Low \\
\hline Security & Iess secure & Mredium secure & High $x$ cure \\
\hline Primary Devices & $\begin{array}{l}\text { Mobile phones, FDAs, } \\
\text { oonsumer } \\
\text { eloctromes, offee and } \\
\text { industrial } \\
\text { zutomation deviess }\end{array}$ & $\begin{array}{l}\text { Notebook oomputers, } \\
\text { deslatop } \\
\text { oomputers, servers, } \\
\text { latest mobiles, iPods, } \\
\text { ete. }\end{array}$ & 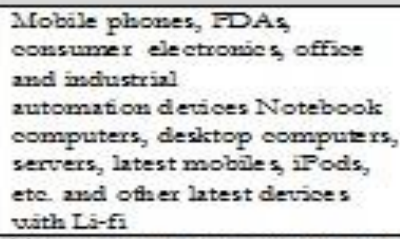 \\
\hline Primary Users & $\begin{array}{l}\text { Traveing emplorses } \\
\text { eloctronios oonsumers } \\
\text { offoe } 2 \text { nd molustrial } \\
\text { vorkers }\end{array}$ & $\begin{array}{l}\text { Corporate empus users } \\
\text { md homes, flats, pubbe } \\
\text { pleces }\end{array}$ & $\begin{array}{l}\text { Trzuling employees, Corporzte } \\
\text { exmpus users and homes, flats } \\
\text { publie places and industrial } \\
\text { zre } 25 \text { pover plants, hospitzls. }\end{array}$ \\
\hline Usege Location & $\begin{array}{l}\text { Anpruthere at le2st two } \\
\text { Bluetooth } \\
\text { derioes exist }\end{array}$ & $\begin{array}{l}\text { Within range of WLANT } \\
\text { infr zstruetuxe, usually } \\
\text { inside } 2 \\
\text { building }\end{array}$ & $\begin{array}{l}\text { Anruhere vihere hght is } \\
\text { zvilibble like roads public } \\
\text { place, homs, offios, ete. }\end{array}$ \\
\hline Stand $x d$ & IEEE 80215 & IEEE $80211 \mathrm{~b}$ & IEEE $\mathrm{BO} 2.15$ \\
\hline Operating Band & ISAC Band at 2.5 ACHz & RF Band & Visible Light band \\
\hline Maximum Members & $\begin{array}{l}7 \text { members can connect } 2 t \\
2 \text { time }\end{array}$ & 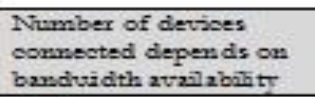 & $\begin{array}{l}\text { Number of receiver s present } \\
\text { under light }\end{array}$ \\
\hline Development Started & 1998 & 1990 & 2011 \\
\hline W'orlóng Concept & Mlaster-s]2ue & Vinous Topologies & Direst binaxt datz serving \\
\hline
\end{tabular}

Figure 5: Comparison of $\mathrm{Wi}-\mathrm{Fi}$ and $\mathrm{Li}-\mathrm{Fi}$

Disadvantages of WI-FI

The following are the basic issues with the $\mathrm{Wi}-\mathrm{Fi}$

1) Efficiency: The efficiency of Wi-Fi is less as it consumes more power. Since the number of devices connected keep on increasing the power drawn keeps on increasing. The base station alone consumes $5 \%$ of energy. Which is a major drawback. 


\section{International Journal of Science and Research (IJSR) \\ ISSN (Online): 2319-7064}

Index Copernicus Value (2015): 78.96 | Impact Factor (2015): 6.391

2) Capacity: The amount of accommodating the people within the available spectrum is a major task with the coming $4 \mathrm{~g}$ and $5 \mathrm{~g}$ technology we are actually running out of space.

3) Range: The typical range of the Wi-Fi is of the order of the ten meters, within this short range when the device to be connected keep on increasing the overlapping of the bandwidth takes place.

4) Reliability: Like all other radio frequency transmission, the wireless networking signals are subject to the interferences which causes a loss of data.

5) Speed: The speed on most of the wireless network is much slower when large amount of data has to be transmitted.

6) Security: Radio waves can penetrate through the walls. They can be intercepted. If someone has knowledge and bad intensions they can misuse it.This causes the major security concern.

\section{Advantages of LI-FI}

The Li-Fi uses the LED bulbs which transmits the data through the light.The light can be any light like infrared ,ultraviolet or even the visible light so there is no need to worry about the spectrum which the belong. The speed is also very much enough to download the movies, music files and large amount of data in very much less time.

It also eliminates the disadvantages of the Wi-Fi such as:

1) Security: Since the light cannot travel through walls this makes it more secure and makes it easier to control who can connect to the network.

2) Capacity: Light has 10000 times more wider bandwidth than the radio waves, also light sources are already installed so there is no need to spend must cost on the installation process and also it has much better capacity.

3) Efficiency: Data transmission through the light is very cheap and the LED consumed less power.

4) Avalability: Availability is not a major issue as the light bulbs are present everywhere the thing is they need to be replaced with the LED bulbs.

With the advent of technology one need not search for the places where they are able to get the network they just need to sit/stand under any form of light and surf the internet as the connection is made possible if the light is present.

\section{Disadvantages of LI-FI:}

The major disadvantage of LI-Fi is that the artificial lights cannot travel through the walls and other opaque materials as that of the radio waves and also other shortcoming is it works only on direct line of sight.

\section{Applications of Li-Fi}

There are numerous applications of Li-fi from public internet access through the street lights to the aircrafts where the $\mathrm{Wi}-\mathrm{Fi}$ is banned due to the interference of the radio waves. The li-fi can also be used in the auto-piloted cars which can communicate through the head lights.

1) EMI Sensitive Environments: On aircraft, Li-fi enabled lighting will allow high data rate connectivity for each and every passenger. It allows connectivity at all the times without the Electromagnetic Interference (EMI) with sensitive radio equipment on the flight deck. The reduction in the cabling also reduces the weight of the aircraft.

2) Augmented Reality: Li-Fi enabled lighting can help the visitors of the museums and galleries to get more information about the object being viewed from the light that illuminates the exhibit using mobile phone or camera.

3) Localisied Advertising: By using shop display lighting with Li-fi enabled it is possible to provide the shoppers online shopping and high street experience and also provide them with the offers and coupons as well as advertising videos.

4) Underwater Communication: Radio waves are absorbed under water but light can travel longer distance in water also so using $\mathrm{Li}-\mathrm{Fi}$ it is possible to transmit data between the sea divers and also it is used in the military operations.

5) Traffic Management: In traffic signals $\mathrm{Li}-\mathrm{Fi}$ can be used which will communicate with the LED lights of the cars which can help in managing the traffic in a better manner and the accident numbers can be decreased. Also, LED car lights can alert drivers when other vehicles are too close.

6) Medical Applications:Operation theatres (OTs) do not allow Wi-Fi due to radiation concerns. Usage of $\mathrm{Wi}-\mathrm{Fi}$ at hospitals interferes with the mobile and pc which blocks the signals for monitoring equipment's. So, it may be hazardous to the patient's health. To overcome this and to make OT tech savvy Li-Fi can be used to accessing internet and to control medical equipment's. This can even bebeneficial for robotic surgeries and other automated procedures.

7) Replacement For Other Technology: IT can be easily used in places where using Bluetooth, Wi-Fietc., are banned.

\section{Future of Li-Fi}

In November 2014, Li-Fi pioneers PureLiFi joined forces with French lighting company Lucibel aiming to bring out Li-Fi enabled products.

PureLiFi already have two products on the market .Li-Flame ceiling unit to connect to an LED light fixture and Fi-Flame desktop unit which connects to a device via USB, both aiming to provide light and connectivity in a single device.

With the integration of the internet of things devices and LiFi will provide wealthier opportunities for the retailers and other business alike. For example, the shop owners can transmit data to multiple customers at a faster rate and quickly.

What's more, reports suggest that Apple may build future iPhones with Li-Fi capabilities. A Twitter user found that within its iOS 9.1 code there were references to Li-Fi written as 'LiFiCapability' hinting that Apple may integrate Li-fi with iPhones in the future. Whether or not $\mathrm{Li}-\mathrm{Fi}$ will live up to its hype is yet to be decided.

\section{Volume 6 Issue 7, July 2017 www.ijsr.net}




\section{International Journal of Science and Research (IJSR)}

ISSN (Online): 2319-7064

Index Copernicus Value (2015): 78.96 | Impact Factor (2015): 6.391

\section{Conclusion}

In this paper I tried to introduce about the technology called $\mathrm{Li}-\mathrm{Fi}$.If this technology becomes justifiably marketed then each every bulb can be used analogous hotspot to transmit the data wirelessly which is a better and cheaper option and if the technology is developed then it will surely replace the demerits of the Wi-Fi.

\section{References}

[1] http://www.ijcta.com/documents/volumes/vol5issue1/ijct a2014050121.pdf.

[2] http://www.techworld.com/data/what-is-li-fi-everythingyou-need-know-3632764/

[3] http://theinstitute.ieee.org/members/profiles/learn-howlifi-works-from-its-inventor-harald-haas

[4] http://www.rfwireless-world.com/Terminology/LiFi-vsWiFi.html

[5] https://www.slideshare.net/shwrvppt/li-fi-tch 